\title{
Prevention and delay in progression of human pancreatic cancer by stable overexpression of the opioid growth factor receptor
}

\author{
IAN S. ZAGON, SHAWN KREINER, JEFFERY J. HESLOP, ANDREA B. CONWAY, \\ CLINTON R. MORGAN and PATRICIA J. McLAUGHLIN \\ Department of Neural and Behavioral Sciences, The Pennsylvania State University \\ College of Medicine, Hershey, PA, USA
}

Received April 4, 2008; Accepted May 30, 2008

DOI: 10.3892/ijo_00000011

\begin{abstract}
This study examined overexpression of the opioid growth factor receptor (OGFr) in pancreatic cancer cells and phenotypic changes in tumorigenicity. Tumors of MIA PaCa-2 cells transfected with OGFr cDNA (OGFr-1) had 3.3 times more OGFr than empty vector (EV) neoplasias, and 4.3 times more OGFr than tumors from wild-type (WT) mice. No differences in OGFr binding were detected between tumors of EV and WT animals. Tumor incidence in OGFr-1 animals was reduced by up to $50 \%$ from EV mice. Latency times for OGFr-1 tumor expression were increased $30 \%$, tumor volume was decreased $70 \%$, and DNA synthesis was reduced $24 \%$ relative to EV mice. Exogenous OGF reduced OGFr-1 tumor volume up to $55 \%$ compared to OGFr-1 mice given vehicle. These data support OGFr gene function as a regulator of cell proliferation that impacts on tumorigenic expression, and suggest that molecular and pharmacological manipulation of OGFr may prevent or delay human pancreatic cancer.
\end{abstract}

\section{Introduction}

Pancreatic cancer is the 4th leading cause of cancer-related deaths in the United States (1). Difficulties in early diagnosis and the highly aggressive malignant behavior of this disease have contributed to the dismal outlook for individuals afflicted with this cancer (2). Although the standard of care drugs (gemcitabine) can prolong survival for advanced pancreatic cancer, there is only a $5 \%$ survival rate 5 years after the initial diagnosis (1) and the median survival duration is 3-6 months (2-4). Novel agents are urgently needed to extend survival $(4,5)$.

Correspondence to: Dr Ian S. Zagon, Department of Neural and Behavioral Sciences, H109, The M.S. Hershey Medical Center, 500 University Drive, Room C3729, Hershey, PA 17033, USA

E-mail: isz1@psu.edu

Key words: pancreatic cancer, overexpression, opioid growth factor, opioid growth factor receptor, tumor growth
The opioid growth factor (OGF), chemically termed [Met $\left.{ }^{5}\right]-$ enkephalin, is a native opioid peptide that is an important regulator of the growth of human pancreatic cancer (6-22). OGF is constitutively expressed, autocrine produced and secreted, and interacts with the OGF receptor (OGFr) to inhibit the growth of pancreatic cancer cells in vitro and in tumor xenografts $(6,8,12-14,16,18,20,22)$. The action of OGF is tonic, stereospecific, reversible, non-cytotoxic and non-apoptotic inducing, not associated with differentiative processes, cell migration, chemotaxis, adhesion, or invasion, serum- and anchorage-independent, and occurs at physiologically relevant concentrations in a wide variety of pancreatic cancers that includes poorly- and well-differentiated human cell lines $(6,8,12,16-21)$. The only opioid peptide, natural or synthetic, that influences the growth of pancreatic cancer is OGF $(8,12)$. Attenuation of OGF in pancreatic cancer cells through: i) disruption of OGF-OGFr interfacing by way of continuous exposure to opioid antagonists (e.g., NTX) $(8,12,16)$, or ii) a decrease in OGF by antibodies to the peptide (8) stimulates cell proliferation. An increase of OGF in pancreatic cancer cells by addition of exogenous OGF depresses cell proliferation $(8,12,13,16,20)$. OGF is targeted to DNA synthesis $(6,8,12,16,20)$ and is directed toward the p21 cyclin-dependent inhibitory kinase (CKI) pathway (20) which delays cells from transiting $G_{1}$ to the $S$ phases of the cell cycle. Molecular evidence for involvement of CKI in OGF action comes from knockdown experiments with CKIs that eliminate the effects of OGF as an inhibitory peptide (22).

The gene for human OGFr is at least $9 \mathrm{~kb}$ in length, and consists of seven exons and six introns $(7,23)$. OGFr is a 677 amino acid protein that includes 7 imperfect repeats of 20 amino acids each and 3 nuclear localization signals $(7,23)$, and has an apparent mass of $62 \mathrm{kDa}(7,23)$. The chromosomal location of the human OGFr is 20q13.3 (23). Although OGFr has pharmacological properties (e.g., recognizes opioids, naloxone reversibility, stereospecificity) of classical opioid receptors, there is no homology of OGFr in terms of nucleotides or amino acids (7). OGFr is located on the outer nuclear envelope and in the nucleus and perinuclear cytoplasm (23). An increase in OGFr by: i) treatment with imidazoquinoline compounds such as imiquimod and resiquimod (22), or ii) transfection of sense cDNA for OGFr $(24,25)$ depresses cell proliferation. A decrease in OGFr by: i) antisense RNA 
$(26,27)$, or ii) knockdown by siRNA for OGFr $(20,22)$ results in an elevation in cell proliferative activity.

In a previous study using tissue culture, overexpression of OGFr at the molecular level in human pancreatic cancer cells resulted in marked decreases in DNA synthesis and cell proliferation (6). The present investigation was directed towards addressing whether amplification of OGFr in human pancreatic cancer cells transplanted into mice contributes to phenotypic changes in tumorigenicity. The results show for the first time that overexpression of OGFr at the molecular level prevents or delays tumor appearance, retards tumor progression, and depresses DNA synthesis of these cancers. Thus, a biologic approach by upregulation of a native component of pancreatic cancer cells, OGFr, under in vivo conditions may provide a novel target to inhibit pancreatic cancer suggesting that molecular and pharmacological strategies could be utilized for the treatment of this deadly neoplasia.

\section{Materials and methods}

Cell lines. Human pancreatic cancer cell line, MIA PaCa-2, was obtained from the American Type Culture Collection, Manassas, VA and maintained in culture with Dulbecco's modified Eagle's medium (DMEM) (Penn State Media Center), containing $10 \%$ heat-inactivated fetal bovine serum, $3.7 \mathrm{~g} / 1 \mathrm{NaHCO}_{3}$ and antibiotics $\left(10^{5} \mathrm{U} / 1\right.$ penicillin, $100 \mu \mathrm{g} / \mathrm{ml}$ streptomycin). Cells were maintained in a humidified atmosphere of $5 \% \mathrm{CO}_{2}$ at $37^{\circ} \mathrm{C}$.

Gene constructs and transfections. A previously described plasmid, pcDNA3.1 + huOGFr (6), was used for obtaining stable expression of human OGFr transgene in human pancreatic cancer cells. In addition, wild-type (WT) MIA $\mathrm{PaCa}-2$ cells were included. Clonal cell lines OGFr-1 and empty vector (EV) were expanded and characterized as reported earlier (6). These cells were analyzed by receptor binding assays to determine OGFr receptor number prior to inoculation into nude mice.

Tumor burden studies in nude mice. Four-week-old male $\mathrm{BALB} / \mathrm{c}$ athymic nude mice were purchased from Harlan Laboratories (Indianapolis, IN), and acclimated to flexiblefilm isolators for one week prior to tumor cell inoculation. Two inoculums $\left(2 \times 10^{6}\right.$ and $\left.5 \times 10^{6}\right)$ of WT, EV, and OGFr- 1 cells were injected subcutaneously into the right scapula region ( $\sim 0.2 \mathrm{ml} /$ mouse $)$ of nude mice.

Mice were observed daily for initial appearance of tumors, and subsequently measured in 2 dimensions using vernier calipers $(12,13)$. Tumor volume was calculated as $1 \mathrm{x} \mathrm{w}^{2} \mathrm{x} \pi / 6$ where $\mathrm{w}$ is the shorter dimension (27). Depending on the experiment, mice were euthanized and tumors removed for analysis at 6 or 7 weeks after tumor cell inoculation.

OGF receptor binding analyses. Cells in tissue culture, as well as tumor tissues, were assayed for OGFr using custom synthesized $\left[{ }^{3} \mathrm{H}\right]-\left[\mathrm{Met}^{5}\right]$-enkephalin (Perkin-Elmer, Boston, MA). Binding assays for cells and tumor tissues followed the procedures by Zagon et al $(6,13)$. Non-specific binding was measured in the presence of unlabeled $\left[\mathrm{Met}^{5}\right]$-enkephalin. Saturation binding isotherms were generated using GraphPad
Prism software; $\mathrm{K}_{\mathrm{d}}$ and $\mathrm{B}_{\max }$ values were provided by computer software.

Immunohistochemistry. To examine for the presence of OGFr, MIA PaCa-2 tumors were excised and frozen in isopentane chilled on dry ice at the time of euthanasia. Within 7 days, tumors were sectioned and stained with ammonium sulfate purified anti-OGFr-IgG (1:200; I0028) (26) diluted in Sorenson's phosphate buffer with $1 \%$ normal goat serum in $0.1 \%$ Triton $\mathrm{X}-100$ for $18 \mathrm{~h}$ at $4^{\circ} \mathrm{C}$; antibodies were previously characterized (26). Following 18-h incubation, sections were washed and incubated with goat-anti-rabbit IgG conjugated to rhodamine. Sections were examined using immunofluorescence optics and an Olympus XI-81 microscope equipped with a digital camera for image capture.

Semi-quantitative densitometry (mean gray values) was utilized to assess relative levels of OGFr using Optimas software (Meyer Instruments, Inc., Houston, TX) (22). A random sample of 10 fields/section from at least 2 sections/ tumor and 2 tumors/treatment were captured using a SPOT RT camera (Diagnostic Instruments, Stirling Heights, MI).

DNA synthesis rates in tumors. On the day of euthanasia, mice were inoculated intraperitoneally with $100 \mathrm{mg} / \mathrm{kg}$ BrdU at 6 and $3 \mathrm{~h}$ prior to receiving an overdose of pentobarbital. These tumors were fixed in formalin for $24 \mathrm{~h}$, processed in paraffin, and sectioned. Sections were stained with anti-BrdU biotin conjugated (1:20) antibodies (Molecular Probes/ Invitrogen, Carlsbad, CA), followed by staining with HRP secondary antibody $(1: 1,000)$ (Chemicon, Temacula, CA). The number of BrdU positive cells was counted in 10 random fields from 5 sections/tumor, 2 tumors/treatment group.

Statistical analyses. The incidence of tumor appearance was analyzed using $\chi^{2}$ tests. Data on latency times, tumor volumes and mass, body weights, and BrdU labeling indexes were analyzed using analysis of variance (ANOVA) with subsequent comparisons using Newman-Keuls tests. In some cases, data were evaluated using two-tailed t-tests. $B_{\max }$ and $K_{d}$ values from binding assays were analyzed using ANOVA. P-values $<0.05$ were considered to be significant.

\section{Results}

Overexpression of OGFr in tumor sections: immunohistochemistry and receptor binding analyses. In order to determine the ramifications from overexpression of OGFr when cells in culture are grown as xenografts in nude mice, receptor binding assays were performed to compare $\mathrm{B}_{\max }$ and $\mathrm{K}_{\mathrm{d}}$ values in cells and tissues (Fig. 1). The $\mathrm{B}_{\max }$ values of transfected OGFr-1 cells in tissue culture and tumors were comparable, and were 2.3- to 4.3-fold greater than those of WT or EV groups. Moreover, no differences between the WT or EV groups were recorded in receptor number for either tissue culture or xenograft preparations. $\mathrm{K}_{\mathrm{d}}$ values for OGFr in WT cells $(2.6 \pm 1.1 \mathrm{nM})$ and tumor tissue $(3.8 \pm 1.4 \mathrm{nM})$ were comparable among all 3 groups of specimens.

To examine the distribution and expression of OGFr in xenografts from human MIA PaCa-2 tumor cells transfected with OGFr-1 or EV, as well as the WT group, immunohisto- 
A

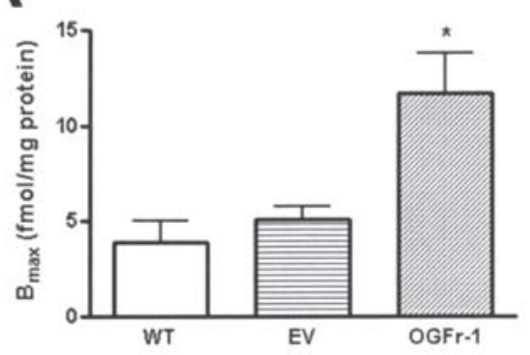

B

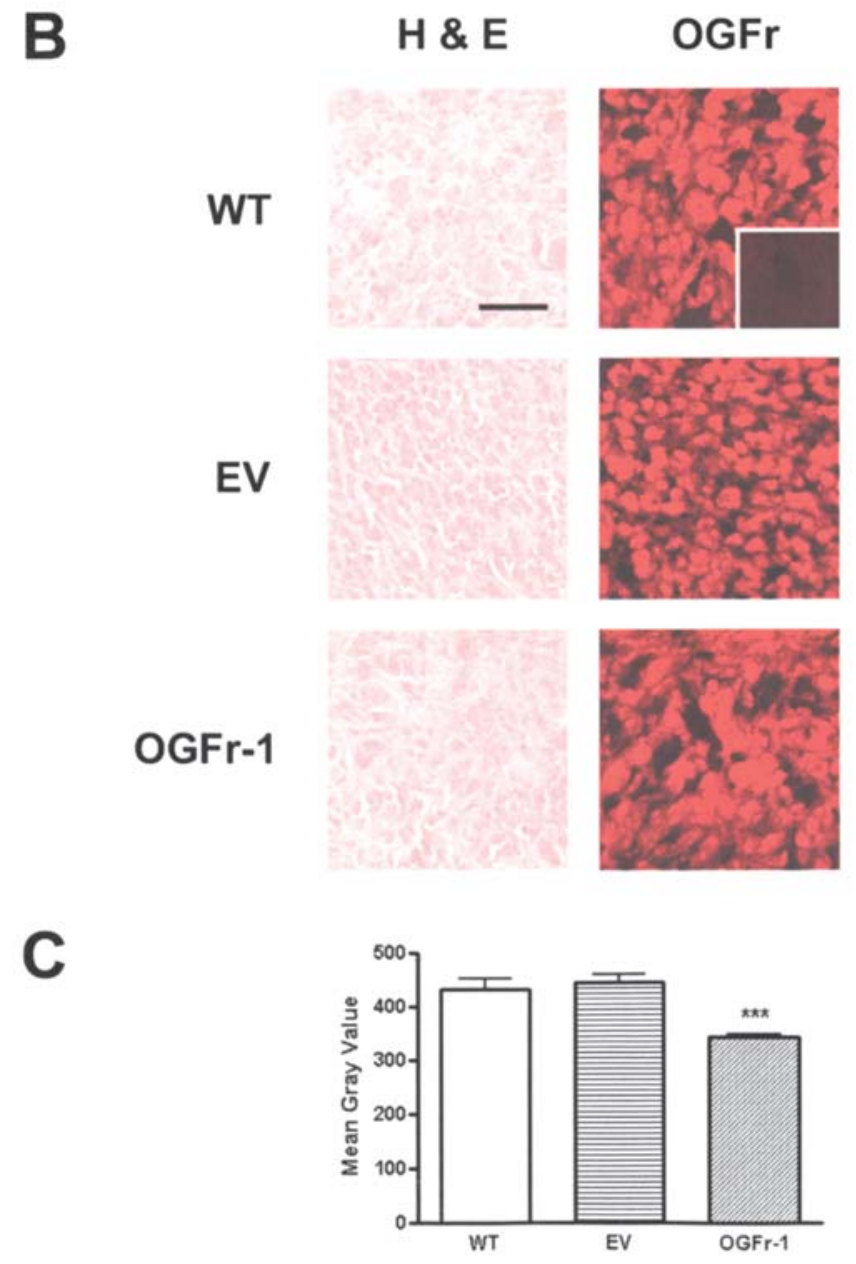

Tumor

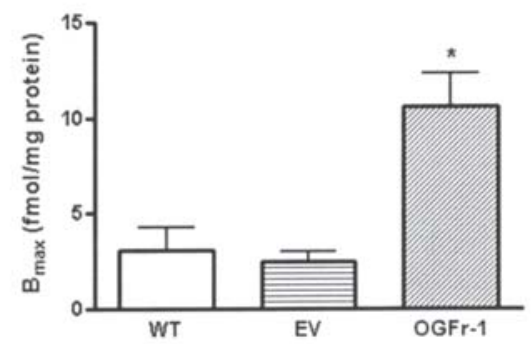

OGFr

Figure 1. Transfection of OGFr in human MIA PaCa-2 pancreatic cancer cells increases translational activity of the receptor in tissue culture cells and xenografts. (A) $\left.\left[{ }^{3} \mathrm{H}\right]-\mathrm{Met}^{5}\right]$-enkephalin binding in nuclear fractions of MIA PaCa-2 log-phase cells in tissue culture at $72 \mathrm{~h}$ after seeding, and in tumor tissues harvested at 42 days. Values $\left(\mathrm{B}_{\max }\right)$ represent means \pm SEM for 4 to 7 binding assays. *Significantly different from the wild-type (WT) and empty vector (EV) group at $\mathrm{p}<0.05$. (B) Photomicrographs showing overexpression of OGFr in tumor tissue. WT, EV, and OGFr-1 tumors were examined on day 42 following tumor cell inoculation. Sections were stained with hematoxylin and eosin (H\&E) or an antibody to OGFr. Note the increased fluorescence in the OGFr-1 specimen. Inset, secondary antibody only. Bar, $30 \mu \mathrm{m}$. (C) Quantitation of OGFr expression in immunohistochemical preparations of tumor tissue from WT, EV, and OGFr-1 specimens using time. Values represent mean \pm SE for at least 10 photodensitometric readings/group from 2 fields/section, 2 sections/ animal/group, and 3 animals/group. ${ }^{* * *}$ Significantly different from the WT and EV groups at $\mathrm{p}<0.001$.

chemistry and quantitative densitometry were employed. The location of OGFr was similar in all groups, with immunopositivity for OGFr being prominent in the cytoplasm, and some immunofluorescent speckling noted in the nucleus (Fig. 1). For sections from all groups of animals with tumors, tumors processed with secondary antibody only showed no staining (see Fig. 1 inset). Photodensitometric measurements (Fig. 1) revealed that exposure times for specimens of tumors from the OGFr-1 group were decreased by $\sim 22 \%$ from that of the WT and EV groups; exposure times of the WT and EV groups were similar. Thus, the decrease in photodensitometric values in OGFr-1 sections reflects the increased fluorescence related to overexpression of OGFr protein.

Overexpression of OGFr in human MIA PaCA-2 cells retards tumor appearance. The overall incidence for a visible tumor in animals injected with EV or OGFr-1 human MIA PaCa-2 cancer cells on days 5, 12, and 15 is presented in Fig. 2A. No 
A
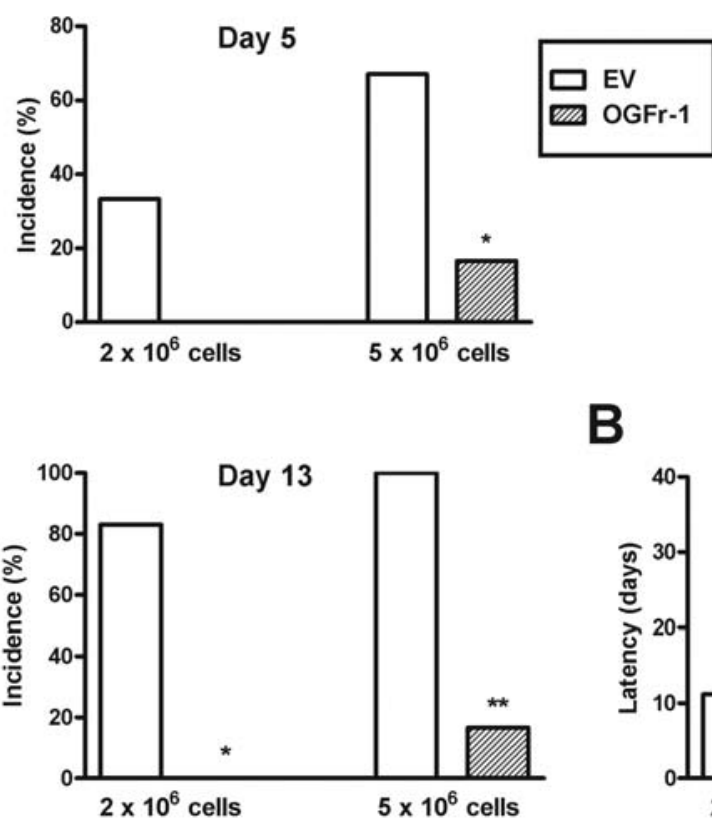

B
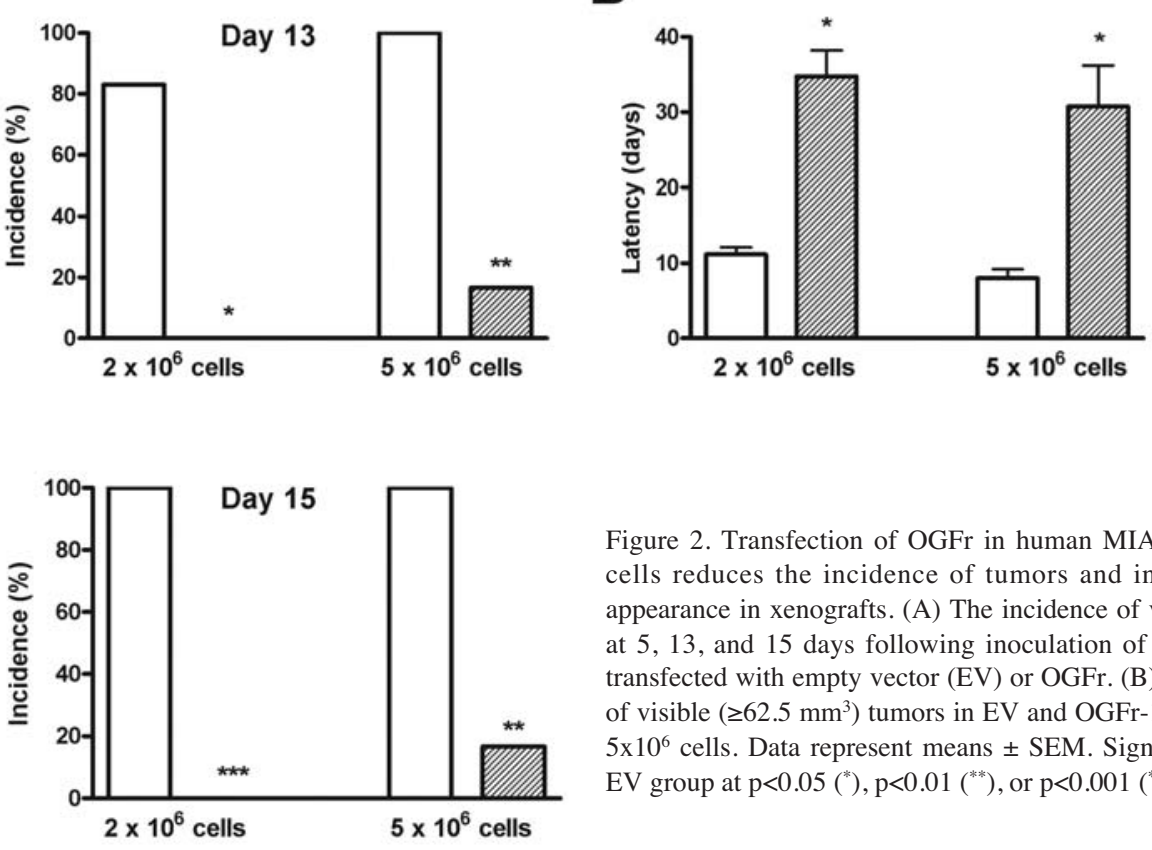

Figure 2. Transfection of OGFr in human MIA PaCa-2 pancreatic cancer cells reduces the incidence of tumors and increases a delay in tumor appearance in xenografts. (A) The incidence of visible tumors $\left(\geq 62.5 \mathrm{~mm}^{3}\right)$ at 5,13 , and 15 days following inoculation of $2 \times 10^{6}$ or $5 \times 10^{6}$ cell stably transfected with empty vector (EV) or OGFr. (B) Latency of the appearance of visible $\left(\geq 62.5 \mathrm{~mm}^{3}\right)$ tumors in EV and OGFr-1 groups receiving $2 \times 10^{6}$ or $5 \times 10^{6}$ cells. Data represent means \pm SEM. Significantly different from the EV group at $\mathrm{p}<0.05\left(^{*}\right), \mathrm{p}<0.01\left(^{* *}\right)$, or $\mathrm{p}<0.001\left(^{(* *}\right)$.

mice in the OGFr-1 group receiving $2 \times 10^{6}$ cells had tumors, in contrast to a 33,80 , and $100 \%$ incidence on days 5,12 , and 15 , respectively, for the EV group. By day $42,50 \%$ of the mice in the OGFr- 1 group receiving $2 \times 10^{6}$ cells had no measurable tumors; the difference from the EV group was significant ( $\mathrm{p}<0.05$ using $\chi^{2}$ analysis).

Injection of $5 \times 10^{6}$ cells into mice revealed a $15 \%$ incidence up to day 15 for mice in the OGFr-1 group, whereas the EV group had a 66\% incidence by day 5 and $100 \%$ incidence by day 13 (Fig. 2A). On day 42, 33\% of the mice in the OGFr-1 group receiving $5 \times 10^{6}$ cells never displayed a measurable tumor; the difference from the EV was not statistically significant.

Evaluation of the latency for expression of measurable tumors over a 42-day period showed that mice receiving $2 \times 10^{6}$ cells the OGFr-1 group had a mean latency time that was 23 days longer than in the EV group (Fig. 2B). For mice injected with $5 \times 10^{6}$ cells the OGFr- 1 group had a mean latency time that was 22 days longer than in the EV group. In both cases, these differences from the OGFr-1 and EV groups were significantly different $(\mathrm{p}<0.05)$.

and data on tumor volumes in mice at days $7,14,21,28,35$, and 42 are presented in Fig. 3 for two different tumor burdens: $2 \times 10^{6}$ and $5 \times 10^{6}$ cells. Beginning at week 4 for animals injected with $2 \times 10^{6}$ cells, mice in the EV group had tumor volumes that were 3.0- to 3.7-fold greater than in OGFr-1 animals. With respect to animals receiving $5 \times 10^{6}$ human pancreatic cancer cells, mice in the EV group had a tumor volume that was 3.4 - to 5.5 -fold greater than in OGFr-1 animals.

Following euthanasia of animals on day 42 , tumor weight was determined. In contrast to a mean tumor weight of $1.1 \pm 0.2 \mathrm{~g}$ for animals in the EV groups, mice in the OGFr-1 groups injected with either $2 \times 10^{6}$ or $5 \times 10^{6}$ cells had tumor weights that were each $0.3 \pm 0.1 \mathrm{~g}$. This reduction of $72 \%$ in both OGFr-1 groups was significant $(\mathrm{p}<0.05)$ in comparison to their EV counterparts.

The body weights of mice in the EV group receiving $2 \times 10^{6}$ or $5 \times 10^{6}$ cells were $31.2 \pm 0.9$ and $31.3 \pm 1.3 \mathrm{~g}$, respectively, and did not differ from mice injected with OGFr-1 cells. Metastases were not observed in organs of the body cavity at the time of death in any treatment group.

DNA synthesis in human MIA PaCa-2 tumors overexpressing OGFr. Assessment of DNA synthesis in animals of the EV and OGFr-1 groups was determined using BrdU (Fig. 4). 

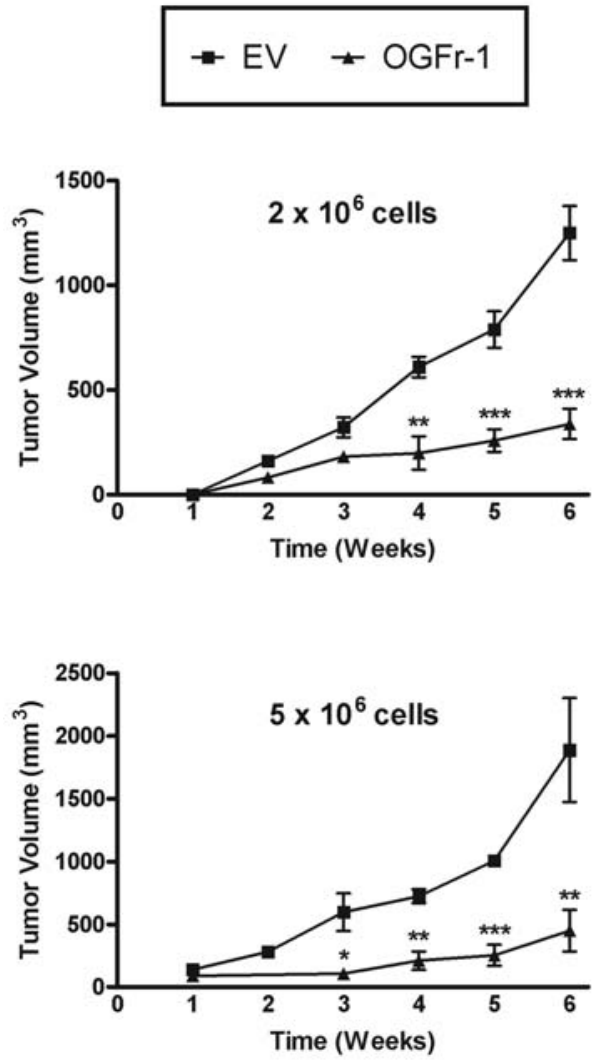

Figure 3 . The growth of tumors as monitored by tumor volume in mice receiving $2 \times 10^{6}$ or $5 \times 10^{6} \mathrm{EV}$ or OGFr-1 cells that expressed a neoplasm over a 6 -week period. Data represent means \pm SEM for at least 5 animals/ group. Significantly different from the EV group at $\mathrm{p}<0.05(*), \mathrm{p}<0.01(* *)$, or $\mathrm{p}<0.001(* * *)$.

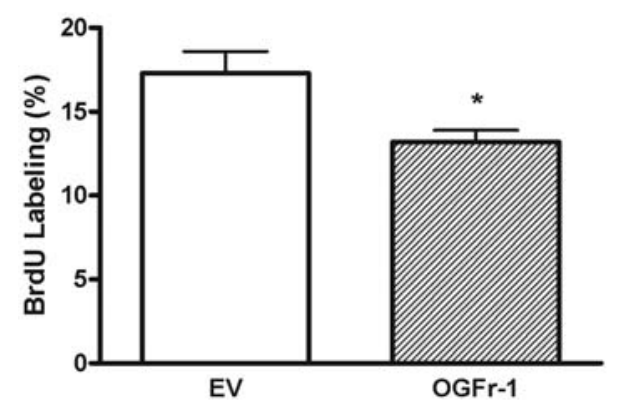

Figure 4. DNA synthesis of EV and OGFr-1 MIA PaCa-2 cells in xenografts. Animals received injections of BrdU $3 \mathrm{~h}$ prior to sacrifice at 42 days. Data represent means \pm SEM. "Significantly different from the EV group at $\mathrm{p}<0.05$.

Examination of tumors at 42 days showed that neoplasias from the OGFr-1 group had 24\% less BrdU-labeled cells compared to mice in the EV group.

OGF potentiates the growth inhibition induced by an overexpression of OGFr. To examine the effects of exogenous OGF on mice with overexpression of OGFr, mice in the OGFr-1 group were injected daily with either $10 \mathrm{mg} / \mathrm{kg}$ OGF

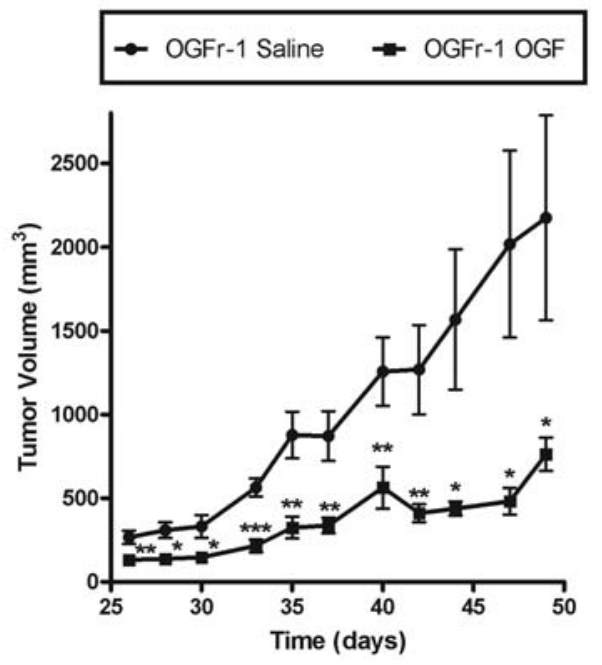

Figure 5. The growth of tumor cells tranfected with OGFr-1 in mice receiving daily injections of $10 \mathrm{mg} / \mathrm{kg}$ OGF or vehicle. Data represent means \pm SEM for 12 animals/group. Significantly different from the EV group at $\mathrm{p}<0.05(*), \mathrm{p}<0.01(* *)$, or $\mathrm{p}<0.001(* *)$.

or an equivalent volume of saline. Determination of tumor appearance on day 30 revealed that mice in both OGFr-1 groups (injected with OGF or saline) had a tumor incidence of $45 \%$. The latency of measurable tumor appearance for mice in the OGFr-1 group receiving vehicle was $29.9 \pm 1.9$ days, and in the OGFr-1 group treated with exogenous OGF the latency was $30.1 \pm 2.4$ days. However, OGFr-1 mice receiving OGF had $37-55 \%$ smaller tumor volumes than the OGFr-1 mice receiving vehicle beginning on day 26 , a time when $\sim 50 \%$ of the mice in each group had a tumor, and continuing to day 49 at which time mice were euthanized (Fig. 5).

\section{Discussion}

The present study provides major insights into the molecular mechanisms of the OGF-OGFr axis. This is the first report that amplification of OGFr in human pancreatic cancer cells has a marked influence in determining the incidence and progression of disease under in vivo conditions. To examine whether tumor transplantation changed the properties of cells overexpressing OGFr in tissue culture, receptor binding assays were used to compare OGFr number in xenografts to those of cells in vitro. The results showed that there was a 3-4-fold increase in $\mathrm{B}_{\max }$ in tumor tissues transplanted with the overexpressing MIA $\mathrm{PaCa}-2$ cells relative to binding capacities measured in WT or EV xenografts. Moreover quantitative densitometric measurements using MIA PaCa-2 tumor tissues revealed more than a $20 \%$ shorter exposure time of the OGFr-1 tumor tissues stained with antibody to OGFr than in tumor tissue from the EV and WT groups. Thus, OGFr-1 cells maintained an overexpression of OGFr when transplanted from tissue culture to nude mice. Moreover, cells and tumors in the EV and WT groups were similar in receptor binding assays and in quantitative densitometric measurements of OGFr staining, supporting that the vector itself was not a confounding influence and justifying the use of only the EV group in subsequent experiments. 
Overexpression of OGFr in human MIA PaCa-2 pancreatic cancer cells markedly changed the characteristics of tumorigenicity. Amplification of OGFr in tumor cells prevented the appearance of neoplasia in 50 and $33 \%$ of the animals receiving 2 and 5 million cells, respectively. In those animals transfected with OGFr and displaying a tumor, the latency for developing a measurable tumor took up to 3-fold longer than the EV group. Moreover, these OGFr-1 tumors grew substantially slower than the EV tumors, being approximately $70 \%$ of the EV tumor size on day 42 (the day of euthanasia for this experiment). Given that the OGF-OGFr axis is targeted to cell proliferation $(16,20)$, the effect of overexpression of OGFr in cancer cells on DNA synthesis warranted investigation. The data show that there was a $24 \%$ decrease in DNA synthesis as measured by BrdU incorporation over a 6-h period, suggesting that endogenous opioids were present and capable of inhibiting cell proliferation. Finally, administration of exogenous OGF to animals receiving tumor cells overexpressing OGFr had notably reduced tumor volumes from those mice receiving the same cells but injected daily with vehicle. These data show that targeted overexpression of the OGF receptor has marked repercussions on the growth and DNA synthesis of human pancreatic cancer cells. Furthermore, addition of exogenous OGF can exacerbate cell responsiveness in tumors with amplified OGFr.

Previous studies have reported that overexpression of OGFr in human pancreatic cancer cells increases OGFr binding and protein expression, extends the doubling time of these cells, decreases cell number and does so in a receptor-mediated and tonically active fashion, and reduces DNA synthesis (6). Addition of exogenous OGF to cells in tissue culture with amplified OGFr even further depressed growth beyond what was observed in OGFr transfected cultures subjected to vehicle (6). The present data are consistent with these earlier observations, and now reveal that when transplanted into nude mice, cells overexpressing OGFr can markedly affect tumor incidence and tumor growth. Thus, the number of OGF receptors is a determinant of the course of a deadly cancer.

The present observations on the effects of additional OGF receptors in pancreatic cancer cells with respect to growth complement and extend those in previous studies regarding changing OGF-OGFr interactions. Corneas of rats transiently transfected with OGFr cDNA with a gene gun in vivo display subnormal DNA synthesis of corneal epithelial cells $(24,25)$ and a depression in wound healing (24). We now make the important observation that stable transfections of $\mathrm{OGFr}$ cDNA into cancer cells that are transplanted into nude mice have marked effects on tumor response. Thus, the ramifications of transfection with OGFr cDNA have far greater implications than just altering individual cell processes.

Clinically, the OGF-OGFr axis has been recorded in biopsy and surgical specimens of human pancreatic cancer using receptor binding (9). Studies on the transplantation of human pancreatic cancer cells into nude mice have revealed that the OGF-OGFr axis is functional in vivo $(12,13)$. Given that pancreatic cancer is the 9th leading cause of mortality in the world (28), and that the survival rate for this neoplasia has not improved substantially in decades (1), strategies for treatment of this lethal neoplasia are needed. In the present study, we found that introduction of additional OGFr into pancreatic cancer cells has a dramatic effect on the expression of these neoplasias in vivo. Therefore, means of upregulating OGFr such as gene therapy $(24,25)$ or agents such as imiquimod (22), perhaps with the combination of additional OGF $(12,13)$ or chemotherapy (12), could provide a useful treatment for inhibiting tumor progression.

\section{Acknowledgements}

We thank Cara L. Keiper and Jody L. Hankins for technical assistance. These studies were supported by a grant from Philip Morris USA Inc. and Philip Morris International.

\section{References}

1. Jemal A, Siegel R, Ward E, Hao Y, Xu J, Murray T and Thun JT: Cancer statistics, 2008. CA Cancer J Clin 58: 71-96, 2008.

2. Li D, Xie K, Wolff R and Abbruzzese JL: Pancreatic cancer. Lancet 363: 1049-1057, 2004.

3. Mancuso A, Calabro F and Sternberg CN: Current therapies and advances in the treatment of pancreatic cancer. Crit Rev Oncol Hematol 58: 231-241, 2006.

4. Ducreux M, Boige V, Goere D, Deutsch E, Ezra P, Elias D and Malka D: The multidisciplinary management of gastrointestinal cancer. Pancreatic cancer: from pathogenesis to cure. Best Pract Res Clin Gastroenterol 21: 997-1014, 2007.

5. Izeradjene $\mathrm{K}$ and Hingorani SR: Targets, trials, and travails in pancreas cancer. J Nat Comprehen Cancer Network 5: 1042-1053, 2007.

6. Zagon IS, Verderame MF, Hankins J and McLaughlin PJ: Overexpression of the opioid growth factor receptor potentiates growth inhibition in human pancreatic cancer cells. Int J Oncol 30: 775-783, 2007.

7. Zagon IS, Verderame MF and McLaughlin PJ: The biology of the opioid growth factor receptor (OGFr). Brain Res Rev 38: 351-376, 2002.

8. Zagon IS, Smith JP and McLaughlin PJ: Human pancreatic cancer cell proliferation in tissue culture is tonically inhibited by opioid growth factor. Int J Oncol 14: 577-584, 1999.

9. Zagon IS, Smith JP, Conter R and McLaughlin PJ: Identification and characterization of opioid growth factor receptor in human pancreatic adenocarcinoma. Int J Mol Med 5: 77-84, 2000.

10. Smith JP, Conter R, Demers LM, McLaughlin PJ and Zagon IS: Elevated levels of opioid growth factor in the plasma of patients with pancreatic cancer. Pancreas 21: 158-164, 2000.

11. Smith JP, Ahmad M, Conter R, Bingaman S, Harvey H, Mauger D, Demers LM, McLaughlin PJ, Stanley W and Zagon IS: Treatment of advanced pancreatic cancer with opioid growth factor. Anticancer Drugs 15: 203-209, 2004.

12. Zagon IS, Jaglowski JR, Verderame MF, Smith JP, LeureduPree AE and McLaughlin PJ: Combination chemotherapy with gemcitabine and biotherapy with opioid growth factor (OGF) enhances the growth inhibition of pancreatic adenocarcinoma. Cancer Chemother Pharmacol 56: 510-520, 2005.

13. Zagon IS, Hytrek SD, Smith JP and McLaughlin PJ: Opioid growth factor (OGF) inhibits human pancreatic cancer transplanted into nude mice. Cancer Lett 112: 167-175, 1997.

14. Zagon IS and McLaughlin PJ: Opioid growth factor receptor is unaltered with the progression of human pancreatic and colon cancers. Int J Oncol 29: 489-494, 2006.

15. Zagon IS, Verderame MF, Allen SS and McLaughlin PJ: Cloning, sequencing, chromosomal location, and function of a cDNA encoding the opioid growth factor receptor (OGFr) in humans. Brain Res 856: 75-83, 2000.

16. Zagon IS, Roesener CD, Verderame MF, Levin RJ and McLaughlin PJ: Cell cycle regulation of human neoplasias by opioid growth factor (OGF). Int J Oncol 17: 1053-1061, 2000.

17. Zagon IS and McLaughlin PJ: Opioids and the apoptotic pathway in human cancer cells. Neuropeptides 37: 79-88, 2003.

18. Zagon IS and McLaughlin PJ: Opioid growth factor (OGF) inhibits anchorage-independent growth in human cancer cells. Int J Oncol 24: 1443-1448, 2004. 
19. Zagon IS and McLaughlin PJ: Opioid growth factor, opioids, and differentiation of human cancer cells. Neuropeptides 39: 495-505, 2005.

20. Cheng F, McLaughlin PJ, Verderame MF and Zagon IS: The OGF-OGFr axis utilizes the p21 pathway to restrict progression of human pancreatic cancer. Mol Cancer 7: 5, 2008.

21. Zagon IS, Rahn KA and McLaughlin PJ: Opioids and migration, chemotaxis, invasion, and adhesion of human cancer cells. Neuropeptides 41: 441-452, 2007.

22. Zagon IS, Donahue RN, Rogosnitzky M and McLaughlin PJ: Imiquimod upregulates the opioid growth factor receptor to inhibit cell proliferation independent of immune function. Exp Biol Med (In press).

23. Zagon IS, Ruth TB and McLaughlin PJ: Nucleocytoplasmic distribution of opioid growth factor (OGF) and its receptor (OGFr) in tongue epithelium. Anat Rec 282A: 24-37, 2005.

24. Zagon IS, Sassani JW, Malefyt KJ and McLaughlin PJ: Regulation of corneal repair by particle-mediated gene transfer of opioid growth factor receptor complementary DNA. Arch Ophthalmol 124: 1620-1624, 2006.
25. Zagon IS, Sassani JW, Verderame MF and McLaughlin PJ: Particle-mediated gene transfer of OGFr cDNA regulates cell proliferation of the corneal epithelium. Cornea 24: 614-619, 2005.

26. Zagon IS, Verderame MF, Allen SS and McLaughlin PJ: Cloning, sequencing, expression, and function of a cDNA encoding a receptor for the opioid growth factor, [Met ${ }^{5}$ enkephalin. Brain Res 849: 147-154, 1999.

27. Shim WSN, Teh M, Mack POP and Ge R: Inhibition of angiopoietin-1 expression in tumor cells by antisense RNA approach inhibited xenograft tumor growth in immunodeficient mice. Int J Cancer 94: 6-15, 2001.

28. Parkin DM, Pisani P and Ferlay J: Global cancer statistics. CA Cancer J Clin 49: 33-64, 1999. 